\title{
Cardiovascular Mortality and Related Risk Factors among Persons with Schizophrenia: A Review of the Published Literature
}

\author{
Anat Fleischman, MD, ${ }^{1,2}$ \\ Ido Lurie, $\mathrm{MD}^{1,2}$
}

\begin{abstract}
Although persons with schizophrenia (PWS) are entitled to health care and medical preventive and curative treatments in accordance with the same standards as other persons, they suffer from excess mortality compared with the general population. The main cause of natural premature death of PWS is attributed to cardiovascular disorders (CVD). We reviewed the studies of PWS, their risk factors and CVD mortality. In every study, PWS have increased risk of CVD mortality. Additionally, most but not all of the studies found increased CVD behavioral risk factors (i.e., smoking, sedentary life style/less physical activity, increased body mass index (BMI)) in PWS. In order to promote better health care to this population, we propose general recommendations to service users and their families, general and mental health professionals and policy makers. Severe mental illness such as schizophrenia should be addressed as a "risk equivalent" for CVD. Awareness of this association should be implemented in routine psychiatric and general medicine practice as well as at national levels for policy makers. Cardiovascular morbidity and mortality should be referred to as a measure of quality of care. Better communication between different physicians and other health care providers, who treat PWS, should be encouraged. This can be accompanied with technological advances (i.e., unified electronic medical record). Understanding of suggested treatment and adherence to recommendations in PWS may be improved by if relatives and friends accompany the patient in medical settings.
\end{abstract}

Key Words: Schizophrenia, cardiovascular mortality, cardiovascular risk factors, health service

Recommended Citation: Fleischman A, Lurie I. Cardiovascular mortality and related risk factors among persons with schizophrenia: a review of the published literature. Public Health Reviews. 2013;34: epub ahead of print.

\footnotetext{
${ }^{1}$ Outpatient ambulatory service, Abarbanel mental health center, Bat-Yam, Israel.

${ }^{2}$ Sackler School of Medicine, Tel Aviv University, Tel Aviv, Israel.
}

Corresponding Author Contact Information: Dr. Ido Lurie at ido.lurie@gmail.com; Abarbanel Mental Health Center, 15 KKL St. Bat-Yam, Israel. 


\section{INTRODUCTION}

Persons with mental disorders are entitled to health care and medical treatments in accordance with the same standards as other persons. ${ }^{1,2}$ However, persons with schizophrenia (PWS) suffer from excess mortality risk from both natural and un-natural (such as suicide, homicide or accidents) causes ${ }^{3,4}$ compared with the general population. Importantly, this gap may have been growing in the last few decades. ${ }^{4}$ The main cause of natural premature death of PWS is attributed to cardiovascular disorders (CVD). ${ }^{5}$ Death rate attributed to CVD has declined in the past decades. Between the years 1998 to 2008, the rate of death attributable to CVD declined by 30.6 percent in the general population of the United States. ${ }^{6}$

Similarly, CVD risk factors show decreases over the past decades. Monitoring for risk factors between the years 1979 to 1996 across 38 populations from 21 countries in four continents, the risk factors are trending downwards in most populations. ${ }^{7}$ However, it seems that PWS do not benefit from this risk reduction. Accordingly, the triple aim of this paper is: 1) to review the growing body of research regarding excess CVD mortality and CVD risk factors among PWS; 2) to describe possible reasons for the excess of CVD mortality (e.g., socio-economic status (SES) inequality, gaps in access to medical treatment); and 3) to suggest recommendations for service users and their families, mental and general health professionals and policy makers.

\section{STUDY SELECTION}

\section{Methods}

We conducted a search of the literature to review major factors related to CVD mortality in PWS, and the CVD risk factors. Based on findings from large cohort and case-control studies from different countries, the main modifiable risk factors-which have been known for decades-are both behavioral (e.g., smoking, sedentary lifestyle) and biological (e.g., hypertension, dyslipidemia, obesity, diabetes mellitus). ${ }^{8-11}$ Similarly, the eight risk factors reported by the World Health Organization (alcohol use, tobacco use, high blood pressure, high body mass index (BMI), high cholesterol, high blood glucose, low fruit and vegetable intake, and physical inactivity) account for 61 percent of cardiovascular deaths. ${ }^{11}$

Accordingly, our search included the following terms: schizophrenia AND mortality AND (cardiovascular OR hypertension OR "metabolic 
syndrome" OR diabetes OR smoking OR "sedentary life style" OR obesity OR dyslipidemia). Our inclusion criteria were: (a) publication type: epidemiological comparative cohort, case-control or cross-sectional studies; (b) published between 1 January 2006 to 1 December 2012; and (c) English language publications. We limited our literature search to this period because a comprehensive systematic-review and meta-analysis published in 2007 reviewed studies until 31 January 2006. Publications were retrieved by an extensive dataset search from PubMed that was conducted in the period from November 2012 to January 2013. Titles and abstracts were read by the authors to determine whether the publication suited the search criteria. Papers that met search criteria were accessed to review the full text. Reviews and meta-analysis were reviewed to find other relevant sources of data.

The initial search yielded 245 papers and searches within reviews gave a total of 253 papers of which 37 were relevant. Papers were excluded if they investigated other psychiatric disorders and/or failed to separate schizophrenia from other psychiatric disorders $(n=11)$, were case reports $(n=7)$, opinion papers $(n=23)$ or reviews $(n=58)$, studies of cardiac and autonomic nervous system functioning $(n=13)$, schizophrenia treatment $(n=8)$, all or other (non-CVD) causes of mortality $(n=13)$, interventions studies $(\mathrm{n}=14)$, non-epidemiological studies and/or without comparison group $(n=25)$ or were not relevant $(n=44)$.

The reviewed studies were grouped into two categories: cardiovascular mortality studies (Ia) and cardiovascular risk factors studies (Ib). The studies are described in reversed order of publication (from late to early). In section II we suggest possible explanations to the findings regarding cardiovascular mortality and risk factors among PWS. Several studies are cited in more than one section as they include relevant data (Table 1 and Table 2).

\section{CVD EXCESS MORTALITY AMONG PWS}

\section{Ia. Cardiovascular mortality studies (Table 1)}

$\mathrm{Wu}$, et al. ${ }^{12}$ reported a case-control study that included 591 PWS after myocardial infarction (MI) in Taiwan that found the inpatient mortality of PWS was 2.7 times higher compared to controls without schizophrenia. Ratliff, et al. ${ }^{13}$ investigated 106 obese PWS. PWS had a vascular age 14 years older than their actual age compared to obese National Health and Nutrition Examination Survey (NHANES) participants without schizophrenia, who had a seven year difference. The probability of experiencing a CVD event within the next ten years was 10.7 percent for obese PWS and 8.5 percent for 


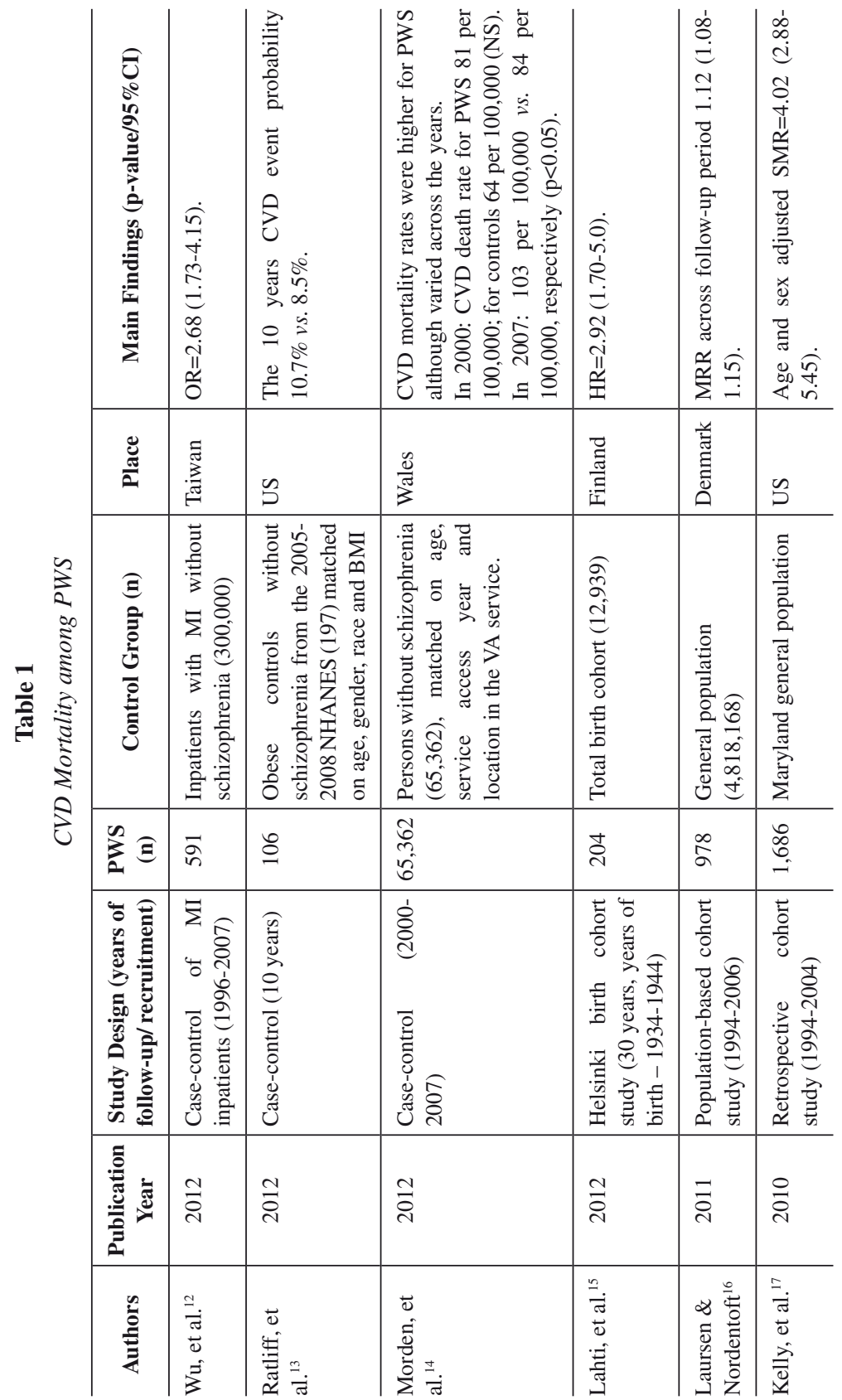




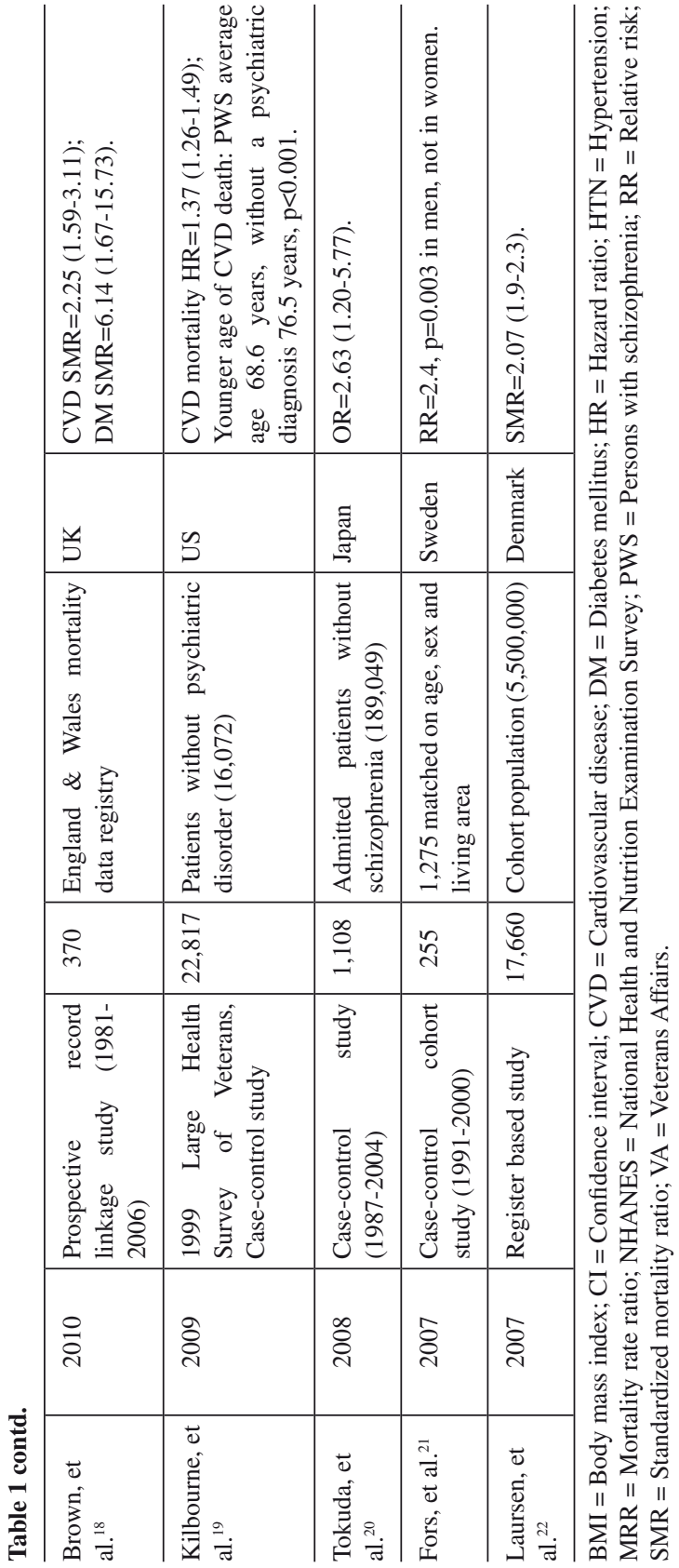


obese NHANES participants $(\mathrm{p}<0.01)$. Morden, et al. ${ }^{14}$ followed 65,362 PWS from the veteran affairs health system in Wales. Compared to controls without schizophrenia, PWS had higher prevalence of diabetes mellitus (DM) and obesity. CVD and hypertension (HTN) were less often diagnosed. CVD mortality* rates were higher for PWS compared to controls without schizophrenia, and varied across the years of study: in the year 2000, the CVD death rate was 81 per 100,000 for PWS compared to 64 per 100,000 for controls without schizophrenia (a non-statistical significant difference). In the year 2007, the CVD death rates were 103 per 100,000 and 84 per 100,000, respectively $(\mathrm{p}<0.05)$. Lahti, et al. ${ }^{15}$ investigated the Helsinki birth cohort $(\mathrm{n}=$ $12,939)$. PWS $(n=204)$ had a higher risk for hospitalization for coronary heart disease (CHD) (hazard ratio (HR) $=1.65,95 \%$ CI 1.03-2.57) and for CHD mortality (HR=2.92, 95\% CI 1.70-5.0). Mortality was even higher in women (HR=6.91, 95\% CI 2.44-19.59 vs. $\mathrm{HR}=2.35$, 95\% CI 1.25-4.43). Laursen and Nordentoft, ${ }^{16}$ in a population-based cohort study in Denmark found that for PWS ( $\mathrm{n}=978$ ) the mortality rate ratio was increased compared to the general population $(1.12,95 \%$ CI $1.08-1.15)$. Kelly, et $a l,{ }^{17}$ in a retrospective cohort of 1,686 PWS treated with antipsychotic (AP) medication, found elevated standardized mortality ratio (SMR) in PWS (ageand sex-adjusted SMR=4.02, 95\% CI 2.88-5.45) compared to the State of Maryland, US, general population, year 2000 rates. Brown, et $\mathrm{al},{ }^{18}$ in a prospective study of 370 PWS found both higher CVD mortality (SMR=2.25, 95\% CI 1.59-3.1) and DM mortality (SMR=6.14, 95\% CI 1.67-1.57). Kilbourne, et al., ${ }^{19}$ in a case-control study of the 1999 Large Health Survey of Veterans, among 22,817 PWS found CVD mortality to be increased (HR=1.37, 95\% CI 1.26-1.49). PWS who died from CVD were more likely to die at a younger age (average age, 68.6 years) than those without a psychiatric diagnosis (76.5 years, $\mathrm{p}<0.001$ ). Tokuda, et al. ${ }^{20}$ compared 1,108 PWS to patients without schizophrenia $(n=189,049)$ both admitted to a general hospital in Japan. For PWS SMR was 1.3 (95\% CI 0.98-1.7) and odds ratio (OR) for CVD mortality was 2.63 (95\% CI 1.2-5.77). Fors, et al. ${ }^{21}$ in a case-control cohort study in Sweden compared all PWS living in the northern catchment area in Uppsala in 1991 to persons without schizophrenia $(n=1,275)$ matched on age, sex and living area from the Swedish national population register. PWS had excess CVD mortality in men (relative risk $(R R)=2.4, p=0.003$ ) but not in women with schizophrenia. Laursen, et al., ${ }^{22}$ in a registry based study of 5.5 million persons born in Denmark found increased mortality from CVD in PWS (SMR=2.07, 95\% CI 1.9-2.3).

\footnotetext{
* CVD related mortality in this study included deaths due to atherosclerosis, hypertension, coronary heart disease, cerebrovascular disease and aortic aneurysm
} 


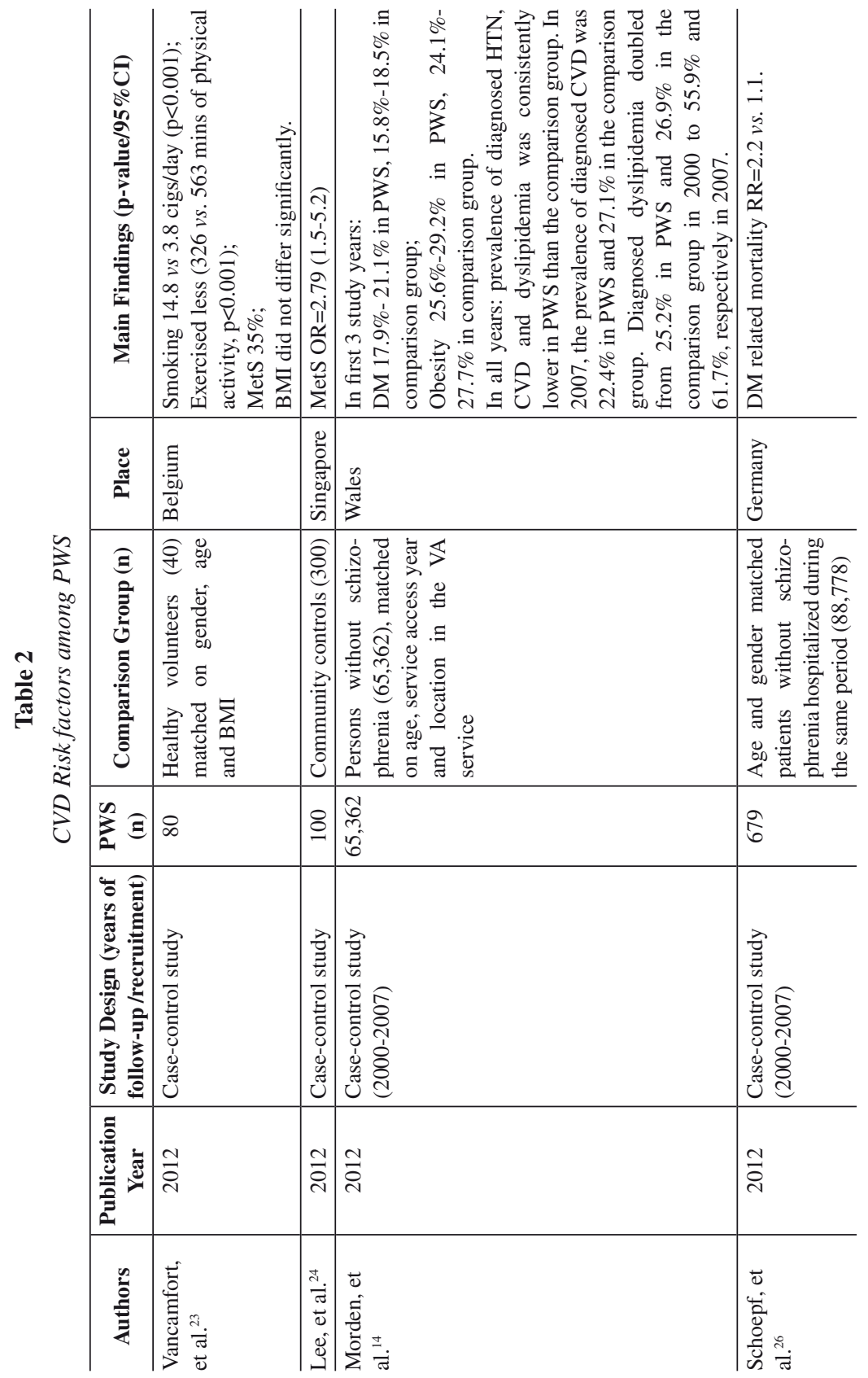




\begin{tabular}{|c|c|c|c|c|c|c|}
\hline 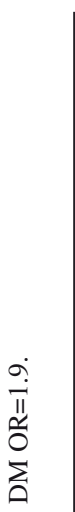 & 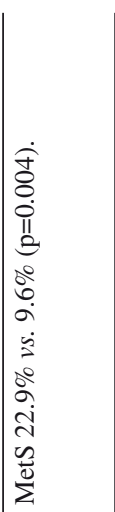 & 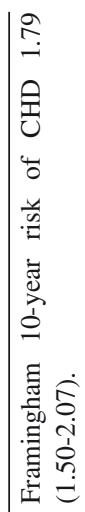 & 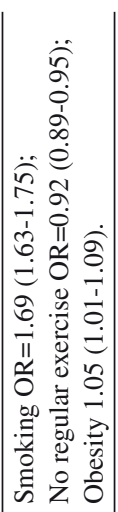 & 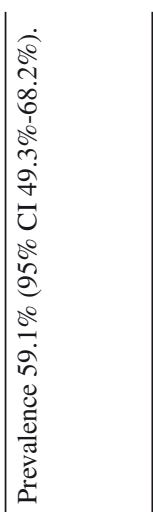 & 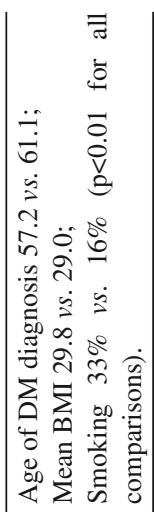 & 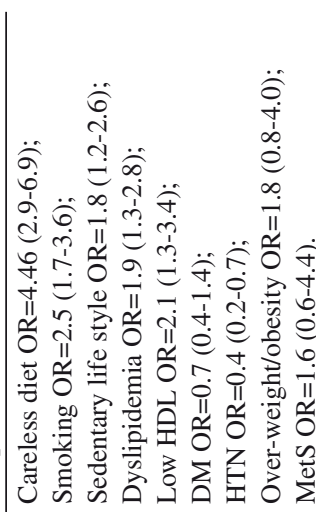 \\
\hline 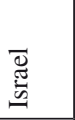 & \begin{tabular}{|l} 
बे \\
音
\end{tabular} & $\Omega$ & $\stackrel{s}{2}$ & $\mathscr{\Omega}$ & 光 & 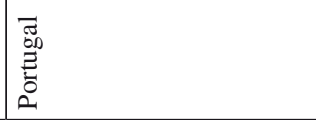 \\
\hline 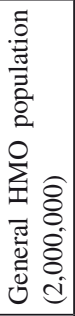 & 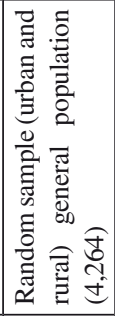 & 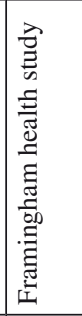 & $\begin{array}{l}2 \\
\sigma \\
0 \\
\infty \\
\infty \\
+\end{array}$ & 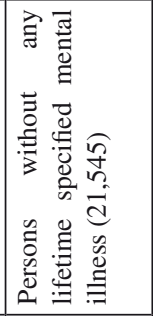 & 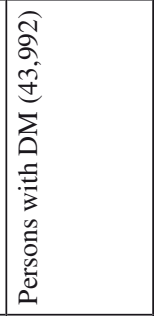 & 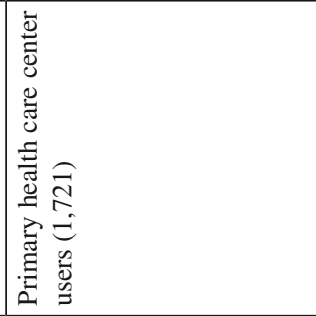 \\
\hline $\begin{array}{l}n \\
i \\
i n\end{array}$ & $\frac{\partial}{m}$ & $\infty$ & $\begin{array}{l}0 \\
n \\
n \\
n \\
n\end{array}$ & $\stackrel{\circ}{1}$ & $\sqrt{n}$ & $\stackrel{2}{\beth}$ \\
\hline 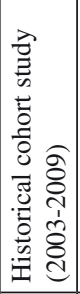 & 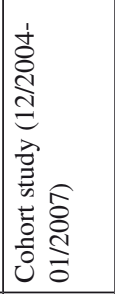 & 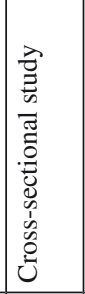 & 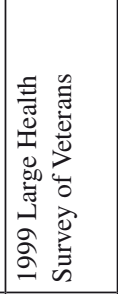 & 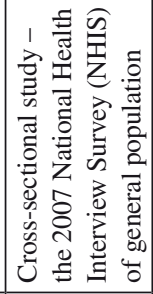 & 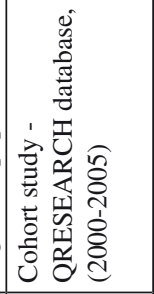 & 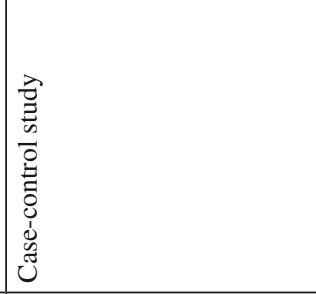 \\
\hline$\frac{\sim}{\stackrel{d}{d}}$ & $\overline{\bar{\sigma}}$ & $\overline{\bar{\sigma}}$ & $\overline{\vec{\Sigma}}$ & $\stackrel{ }{\stackrel{2}{ }}$ & $\stackrel{\circ}{\stackrel{2}{ }}$ & 음 \\
\hline 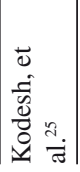 & $\mid$ & 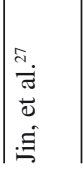 & 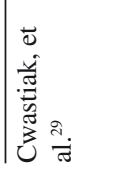 & 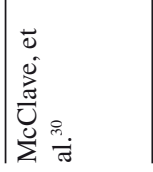 & 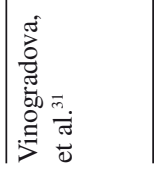 & 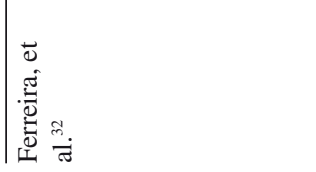 \\
\hline
\end{tabular}




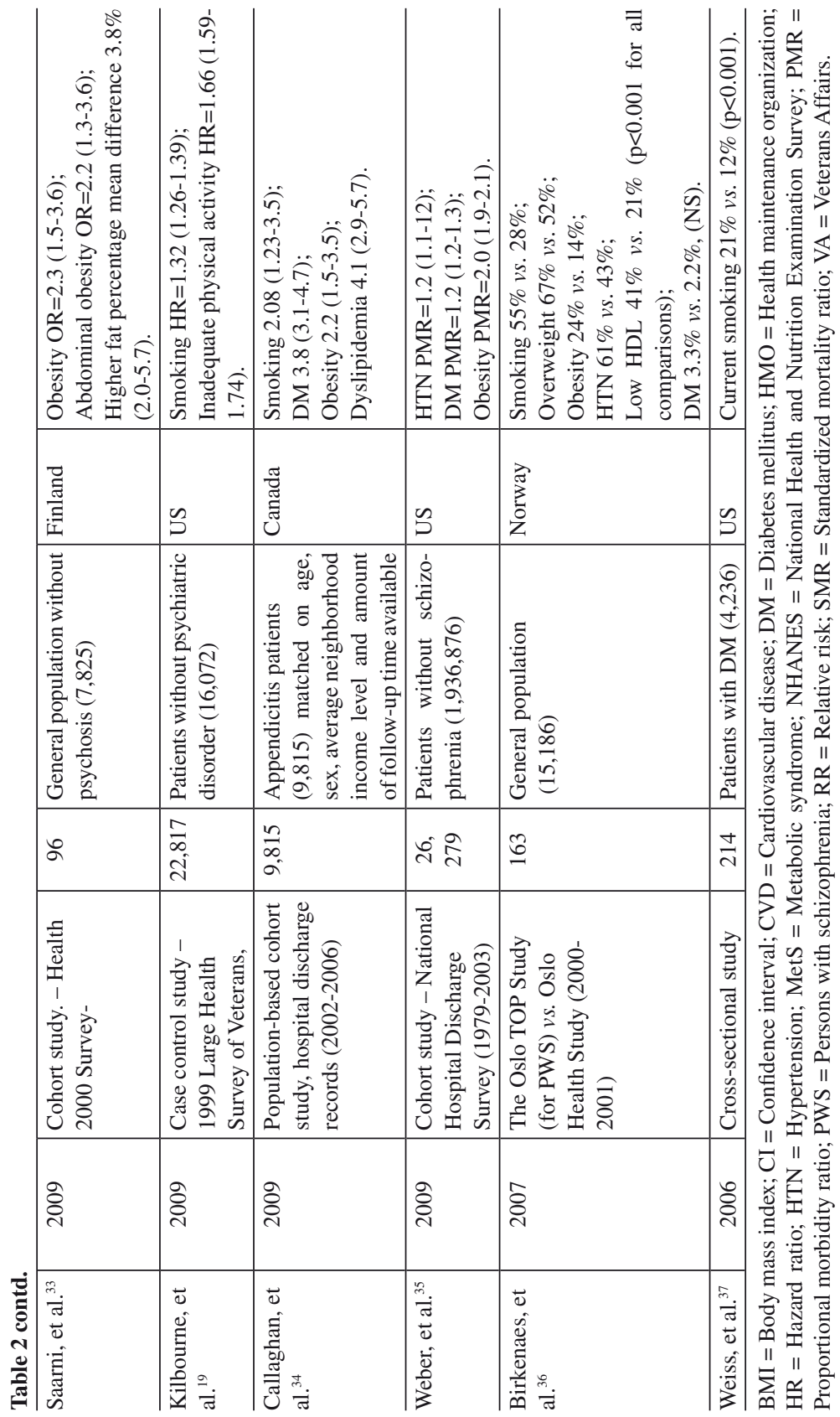




\section{Ib. Cardiovascular risk factors studies (Table 2)}

Vancampfort, et al., ${ }^{23}$ in a study of 80 PWS (both hospitalized and outpatients) in Belgium did not find a significant difference in BMI compared to 40 controls without schizophrenia $(\mathrm{BMI}=26.3$ vs. 25.7, respectively, $\mathrm{p}=0.53)$. Other risk factors were significantly increased; PWS smoked more (14.8 vs. 3.8 cigarettes/day, $\mathrm{p}<0.001$ ), exercised less (326 vs. 563 minutes of physical activity per week, $\mathrm{p}<0.001$ ), and 35 percent of PWS met the International Diabetes Federation criteria for metabolic syndrome (MetS). In a prospective case control study of 100 PWS from Singapore, Lee, et al. ${ }^{24}$ found 46 percent of PWS had MetS, 2.8 times more often than controls (95\% CI 1.50-5.2). In a study cited above, Morden, et al. ${ }^{14}$ followed 65,362 PWS from the veterans affairs health system in Wales compared to controls without schizophrenia between 2000 to 2006. In the earlier years, DM and obesity were more prevalent among PWS relative to the comparison group. DM affected 17.9 percent to 21.1 percent of PWS in the first three study years and 15.8 percent to 18.5 percent of the comparison group. In those years, the prevalence of obesity was also greater among PWS $(25.6 \%$ to $29.2 \%$ ) relative to the comparison group (24.1\% to $27.7 \%$ ). These differences diminished in later years. In all years, the prevalence rates of diagnosed HTN, CVD and dyslipidemia were consistently lower in the schizophrenia than the comparison group. In 2007, the prevalence rate of diagnosed CVD was 22.4 percent in the PWS and 27.1 percent in the comparison group. Both groups experienced a substantial increase in CVD risk factors diagnoses over the study period. Diagnosed dyslipidemia nearly doubled from 25.2 percent in PWS and 26.9 percent in the comparison group in 2000 to 55.9 percent and 61.7 percent, respectively, in 2007. Kodesh, et al. ${ }^{25}$ in a historical cohort study compared 5,732 PWS to health maintenance organization members without psychiatric diagnosis in Israel. PWS were more likely to be diagnosed with $\mathrm{DM}(\mathrm{OR}=1.9$, significance not mentioned). Schoef, et al. ${ }^{26}$ in a case control study of 679 PWS in Germany found higher prevalence of DM among PWS and higher prevalence of DM in PWS who died. The effect of DM on mortality was twice higher among PWS (RR=2.2, 95\% CI 1.4-3.6 vs. $\mathrm{RR}=1.1,95 \%$ CI 1.1-1.2). Jin, et al., ${ }^{27}$ in a cross-sectional study of middle aged and older PWS in the US found that the Framingham ten-year risk of CHD was increased by 1.79 (95\% CI 1.52.07) compared to the general population. In a cohort study in Turkey, Yazici, et al. ${ }^{28}$ found MetS in significantly higher rates in PWS in the younger age group (20-29 years old) compared to the general population (22.9\% vs. 9.6\%, p=0.004). Cwastiak, et al. ${ }^{29}$ in the 1999 Large Health Survey of Veterans cohort study of 501,161 individuals in the US, of whom three perferrcent were diagnosed with schizophrenia, found increased rates 
of several risk factors: smoking $(\mathrm{OR}=1.69,95 \%$ CI 1.63-1.75), no regular physical exercise $(\mathrm{OR}=0.92,95 \%$ CI $0.89-0.95)$, and obesity $(\mathrm{OR}=1.05$, 95\% CI 1.01-1.09).

McClave, et al. ${ }^{30}$ reported the lifetime prevalence of smoking in the cross-sectional study of the 2007 National Health Interview Survey (NHIS) in the US general population. The survey included a household interview survey of the non-institutionalized population with 23,393 respondents: 7.8 percent of the general population reported having at least one lifetime diagnosis of selected mental illnesses (i.e., bipolar disorder, phobias) and of those, 150 were PWS. PWS had the highest prevalence of age-adjusted current smoking $(59.1 \%, 95 \%$ CI $49.3 \%-68.2 \%)$.

Vinogradova, et al., ${ }^{31}$ in a longitudinal cohort study of 43,992 persons with DM conducted in the United Kingdom, 257 also diagnosed with schizophrenia, found persons with both diagnoses were younger at diagnosis of DM (61 years old vs. 65 years old), had a higher mean BMI (29.8 vs. $29.0)$ and more individuals were smokers $(33 \%$ vs. $16 \%)(\mathrm{p}<0.01$ for all comparisons). Persons with both diagnoses had an increased risk of death compared with those with DM alone (OR=1.5, 95\% CI 1.2-2.0). Ferreira, et al. ${ }^{32}$ found in a case control study of 125 PWS in Portugal that compared to controls, PWS had increased rates of "careless" diet (as defined in the paper) $(\mathrm{OR}=4.46,95 \%$ CI 2.9-6.9), smoking $(\mathrm{OR}=2.5$, 95\% CI 1.7-3.6), sedentary life style $(\mathrm{OR}=1.8,95 \%$ CI 1.2-2.6), dyslipidemia $(\mathrm{OR}=1.9,95 \%$ CI 1.3 2.8) and low HDL (OR=2.1, 95\% CI 1.3-3.4). Rates of DM, over-weight/ obesity and MetS did not differ between groups. Surprisingly, HTN was less prevalent in PWS (OR=0.4, 95\% CI 0.2-0.7). PWS had higher rate of untreated risk factors, including HTN (OR=3.79, 95\% CI 1.63-8.81), DM $(\mathrm{OR}=3.79,95 \%$ CI 2.06-7.35), and dyslipidemia $(\mathrm{OR}=6.38$, 95\% CI 1.73 23.59). A difference with borderline significance was found in the ten-year absolute risk of CVD between cases and controls aged 40 years and older $(\mathrm{p}=0.05)$. Saarni, et al. ${ }^{33}$ in a cohort study in the Health 2000 Survey of 8,028 persons in Finland, including 96 PWS, found that schizophrenia was associated with obesity (OR=2.3, 95\% CI 1.5-3.6), abdominal obesity $(\mathrm{OR}=2.2,95 \% \mathrm{CI} 1.3-3.6)$ and with higher fat percentage (mean difference $3.8 \%, 95 \%$ CI 2.0-5.7) than in the remaining sample. After further adjusting for current AP treatment, education, diet and smoking, schizophrenia remained associated with obesity $(\mathrm{OR}=1.9,95 \% \mathrm{CI} 1.1-3.6)$ and abdominal obesity (OR=3.8, 95\% CI 1.5-9.4).

Kilbourne, et al., ${ }^{19}$ in a case-control study of 22,817 PWS in the 1999 Large Health Survey of Veterans in the US, found increased rates of risk factors: smoking ( $\mathrm{HR}=1.32,95 \% \mathrm{CI} 1.26-1.39)$ and inadequate physical activity (HR=1.66, 95\% CI 1.59-1.74). Callaghan, et al. ${ }^{34}$ in a cohort study 
in Canada of 9,815 PWS found that PWS were more likely to be admitted with a diagnosis of CVD compared to persons admitted for appendicitis ( $\mathrm{HR}=1.43$, 95\% CI 1.22-1.69). PWS smoked more (0.8\% vs. $0.4 \%$, $\mathrm{p}<0.001)$, had higher rates of DM $(4.6 \%$ vs. $1.3 \%, \mathrm{p}<0.001)$ and dyslipidemia $(0.9 \%$ vs. $0.3 \%, \mathrm{p}<0.001)$. Weber, et al. ${ }^{35}$ in a cohort study of the National Hospital Discharge Survey, 1979-2003, in the US, found higher proportional morbidity ratio (PMR) of HTN (PMR $=1.2,95 \%$ CI 1.1-1.2), $\mathrm{DM}(\mathrm{PMR}=1.2,95 \%$ CI 1.2-1.3), and obesity $(\mathrm{PMR}=2.0,95 \%$ CI $1.9-2.1)$. Birkenaes, et al., ${ }^{36}$ in a study of 163 PWS (from the Oslo Thematic Organized Psychosis (TOP) study) compared to 15,186 persons from the Oslo Health Study 2000-2001, found that PWS smoked more (55\% vs. $28 \%)$, were overweight ( $67 \%$ vs. $52 \%)$ or obese ( $24 \%$ vs. $14 \%)$, had HTN (61\% vs. 43\%) and had low HDL (41\% vs. 21\%) $(\mathrm{p}<0.01$ for all comparisons). However, no significant difference was found in DM rates (3.3\% vs. $2.2 \%$ ). Weiss, et al., ${ }^{37}$ in a study of 4,236 persons with DM, 214 of them with a diagnosis of schizophrenia, found that PWS were more likely to be current smokers ( $21 \%$ vs. $12 \%, \mathrm{p}<0.001)$.

\section{POSSIBLE REASONS FOR EXCESS MORTALITY AMONG PWS}

To explain these mortality and risk factors gaps, we reviewed several social and behavioral risk factors that are related to both schizophrenia and CVD.

\section{Effects of anti-psychotic medication on mortality}

The effect of AP medication on CVD and mortality (both all-cause and CVD cause) is not clear. AP medication may cause weight gain, dyslipidemia, DM and arrhythmia, however there are contradicting data regarding mortality. We present studies that were found in our literature review and were found relevant to this section.

Otano, et al. ${ }^{38}$ in a prospective observational study of PWS $(n=19)$ in Spain found 26 percent of PWS developed MetS after six months of treatment with AP medication. The postmarketing open label study comparing ziprazidone with olanzepine (ZODIAC) ${ }^{39}$ mortality rates after one year of treatment did not find a significant difference in mortality RR. RR ranged according to the definition of CVD mortality (narrow $v s$. broad definition) from 0.38 (95\% CI 0.1-1.41) to 1.6 (95\% CI 0.84-3.05), respectively. Truyers, et al. ${ }^{40}$ in a retrospective cohort study of first episode of psychosis found an increased risk for DM (HR=1.77, 95\% CI 1.1-2.83). The risk was significant only for second generation antipsychotic (SGA) medication treated PWS (HR=2.46, 95 \% CI 1.29-4.71). Kelly, et al., ${ }^{17}$ in a 
retrospective cohort found elevated SMR in PWS treated with antipsychotics (clozapine: $\mathrm{OR}=4.70,95 \%$ CI 3.19-6.67; risperidone: $\mathrm{OR}=2.88$, 95\% CI 1.38-5.30; no significant difference between medications) compared to year 2000 rates for the State of Maryland, US, general population. Woo, et al., ${ }^{41}$ in a retrospective study of PWS treated eight weeks with either clozapine or olanzepine found an increase in both systolic $(+3.2 \mathrm{mmHg} \pm 11.3 \mathrm{vs}$. -0.7 $\mathrm{mmHg} \pm 8.8, \mathrm{p}=0.02)$ and diastolic $(4.2 \mathrm{mmHg} \pm 8.5$ vs. $0.2 \mathrm{mmHg} \pm 7.9$, $\mathrm{p}=0.002$ ) blood pressure in the clozapine prescribed group. Weight increased in both groups but no change was noted in fasting glucose, cholesterol or triglyceride levels. Jerrel, et al. ${ }^{42}$ investigated medical and pharmacy claims of 2,231 PWS in the South Carolina Medicaid program. Rates of obesity, dyslipidemia and DM were lower than the general population, possibly due to under-diagnosis of these conditions. HTN rate was higher among PWS (42\% vs. 34\%, no significance mentioned). The odds of developing these cardio-metabolic sequels did not change after initiation of AP treatment and were not related to any specific AP medication compared to haloperidol.

Tiihonen, et al., ${ }^{43}$ in an 11-year follow-up of mortality in PWS found a decrease in the life expectancy gap between PWS and the general population (22.5 vs. 25 years) despite the rise in use of SGA from 13 percent to 64 percent during the follow-up period. All causes mortality was decreased for clozapine compared to perphenazine $(\mathrm{HR}=0.74,95 \% \mathrm{CI} 0.60-0.91)$ and increased for other AP medications ( $\mathrm{HR}=1.45,95 \%$ CI 1.24-1.69). The effect of clozapine was more prominent in mortality rates from suicide $(\mathrm{HR}=0.34$, 95\% CI 0.20-0.57). However, CVD mortality rates did not show a significant difference between medications. Newcomer, et al., ${ }^{44}$ in a multicenter randomized double-blind study comparing olanzepine and aripiprazole found after 16 weeks of treatment a decrease in weight $(-1.8$ vs. $1.4, \mathrm{p}<0.001)$, total cholesterol (-9.5 vs. $-3.3, \mathrm{p}=0.005)$, non-HDL cholesterol $(-13.2$ vs. -2.6 , $\mathrm{p}<0.001)$ and an increase in HDL cholesterol $(1.7$ vs. $-5.9, \mathrm{p}=0.002)$ in the aripiprazole compared to the olanzepine group. Tirupati and Chua, ${ }^{45}$ in a cross sectional study of both inpatient and community-based rehabilitation service users $(n=221)$, found the prevalence of obesity in PWS was nearly threefold of the rate reported among Australian adults (59\% vs. 21\%), although the source of data regarding non-PWS population was not mentioned. The prevalence of MetS among the PWS treated with AP medication was more than double the rate observed among Australian adults (68\% vs. 29\%, no significance mentioned). The highest prevalence in MetS was found in patients taking more than one SGA (78\%), clozapine with another AP medication (77\%), combination of first generation AP medication and SGA (72\%), though differences were not significant. Hagg, et al., ${ }^{46}$ in a cross-sectional study in Sweden found that the prevalence rate of MetS was 
34.6 percent (95\% CI 28.8-40.3), clozapine-treated PWS reached the highest prevalence of MetS (48\%, 95\% CI 34-62). Joukamaa, et al. ${ }^{47}$ in a 17 years follow-up study based on the Mini-Finland Health Survey (1978-1980) $(n=7,217)$, found that the number of AP medications prescribed at the time of the baseline survey was related to subsequent mortality. Of the 99 PWS, 20 were not taking AP medication at baseline, 31 one drug, 34 two drugs and 14 three drugs or more. The mortality relative risk for PWS taking no neuroleptic, one, two and three or more neuroleptic drugs were 1.29 (95\% CI 0.53-3.11), 2.97 (95\% CI 1.64-5.38), 3.21 (95\% CI 1.93-5.35) and 6.83 (95\% CI 3.4013.71) respectively compared with persons without schizophrenia. Lamberti, et al.. ${ }^{48}$ compared outpatients PWS ( $\mathrm{n}=93$ ) with a matched NHANES group of subjects ( $\mathrm{n}=2,701)$. A total of $50(53.8 \%)$ PWS treated with clozapine met criteria for the MetS, compared to $369(20.7 \%$, p < 0.001$)$ subjects within the NHANES group $\left(\chi^{2}=47.84, \mathrm{df}=1, \mathrm{p}<0.001\right)$. In a secondary analysis excluding the subgroup with a BMI less than $25 \mathrm{~kg} / \mathrm{m}^{2}$, the prevalence of MetS among NHANES subjects was 34.1 percent, a rate that remained significantly lower than that of the clozapine group $\left(\chi^{2}=20.03, \mathrm{df}=1, \mathrm{p}<0.001\right)$.

\section{Socio-economic status (SES) and social fragmentation}

Low SES (measured by income and educational level) is associated to both schizophrenia and CVD. Decades of research in different countries and in diverse ethnic groups indicate the inverse association of individual ${ }^{49}$ and community/neighborhood ${ }^{50,51} \mathrm{SES}$ with schizophrenia, with higher prevalence rates among people in lower SES, both in men and women. The ratio of lifetime prevalence of schizophrenia among low versus high SES persons was 2.4. ${ }^{52}$ Increased schizophrenia incidence rate was found to be in areas of increased inequality. ${ }^{53}$ Also, data from high-income countries showed that lower SES, both individual and neighborhood, constitute an elevated risk for CVD morbidity, mortality and poorer prognosis. ${ }^{54,55}$ For example, in a European study low SES among adults was found to be independently associated with increased risk of ischemic heart disease mortality in both men and women $(R R=1.6,95 \%$ CI 1.5-1.60, and $R R=2.1,95 \%$ CI 1.98-2.3, respectively).$^{56}$ Beyond individual SES, neighborhood SES, which is the socioeconomic characteristics of the neighborhood in which a person lives, is strongly associated with long-term survival after MI. ${ }^{57}$ Data regarding lowincome and middle-income countries are less consistent.

In high-income countries, lower SES is also associated with specific CVD risk factors, including: DM, ${ }^{58-60}$ even in a relatively highly educated cohort study ${ }^{61}$; HTN ${ }^{62,63}$; obesity ${ }^{64,65}$; and sedentary life style. ${ }^{64,66}$ The combined impact of specific CVD individual risk factors on total risk is 
multiplicative rather than additive,${ }^{67}$ so there is a markedly increased risk of CVD and rates of premature disease among individuals of low SES.

The impact of SES on CVD risk factors is complex and is probably mediated by interaction of behavioral and modifiable risk factors. Analogous to the classical debate regarding the social causation versus the social selection of schizophrenia, there is an on-going debate whether CVD mortality is related to the multiple modifiable behavioral risk factors related to low SES only, ${ }^{68}$ or that SES contributes additional risk beyond those risk factors. However, the result is the same. PWS are more likely to be of lower SES and to have increased risk for CVD risk factors and CVD mortality.

Another social indicator that may be involved in the association of CVD and schizophrenia is social fragmentation (measured by the social fragmentation index, SFI). SFI is related to higher incidence of psychosis and schizophrenia. ${ }^{69-71}$ This finding was unrelated to neither area-level deprivation nor ethnic composition. Social fragmentation is also associated with CVD risk factors. Data indicate increased incidence of MI in both materially-deprived and socially-fragmented contexts, even when controlled for individual social risk factors. ${ }^{72}$ In the Stockholm Heart Epidemiology Program (SHEEP) study, the adjusted RR of MI in the top quartile of materially-deprived areas was 2.0 (95\% CI 1.3-3.1) and 1.6 (95\% CI 1.2-2.1) for women and men, respectively. Adjusted RR of MI for the top quartile of socially fragmented areas was 1.6 (95\% CI 1.0-2.5) for women, and 1.4 (95\% CI 1.0-1.8) for men.

\section{Access to and quality of medical care}

PWS may suffer from under-diagnosis and under-treatment of their medical co-morbidity. ${ }^{73}$ They may be exposed to inferior quality of care in medical health service delivery. ${ }^{74}$ PWS may also report lower level of satisfaction from their medical care service. ${ }^{75}$ Specifically, there may be a lower level of quality of treatment following MI in PWS. As was shown in a meta-analysis from 2010 following cardiovascular events, ${ }^{76}$ PWS have 47 percent lower rates $(\mathrm{RR}=0.53,95 \% \mathrm{CI} 0.4-0.64)$ of the usual invasive coronary revascularization interventions, with significantly lower receipt of coronary artery bypass graft $(\mathrm{CABG})(\mathrm{RR}=0.69,95 \% \mathrm{CI} 0.55-0.85)$ and percutaneous transluminal coronary angioplasty (PTCA)/percutaneous coronary intervention $(\mathrm{PCI})(\mathrm{RR}=0.50,95 \% \mathrm{CI} 0.34-0.75)$. Findings from a recent study that was published after this meta-analysis show similar results; $\mathrm{Wu}$, et al., ${ }^{12}$ as was cited above, in a case-control study of 591 PWS after MI in Taiwan found that when compared to persons without schizophrenia, PWS were less likely to go through catheterization and revascularization after a cardiovascular 
event (Adjusted $\mathrm{OR}=0.37,95 \%$ CI $0.26-0.53$ for catheterization, Adjusted $\mathrm{OR}=0.35,95 \% \mathrm{CI} 0.24-0.51$ for any PTCA/CABG). This was associated with 2.7 higher inpatient mortality rate for PWS.

There may also be a lower level of quality of medical record management. In a case-control study comparing PWS ( $\mathrm{n}=195)$ with persons with asthma and the general population, PWS were half as likely as asthma controls and general population controls to have blood pressure $(\mathrm{OR}=0.51,95 \% \mathrm{CI}$ 1.35-0.73) and cholesterol levels (OR=0.50, 95\% CI 0.31-0.82) recorded, and were also less likely to have smoking status noted $(\mathrm{OR}=0.60,95 \% \mathrm{CI}$ 0.41-0.85). ${ }^{77}$ PWS from the Helsinki birth cohort received less lipidlowering (HR=0.47, 95\% CI 0.27-0.80) and antihypertensive drug treatments (HR $=0.37,95 \%$ CI 0.22-0.61). ${ }^{15}$ Over time, PWS may experience a low frequency and decreasing trajectory of primary care, as was shown in a retrospective study from the US Veterans Healthcare Administration system $^{78}$ of persons with DM only ( $\left.\mathrm{n}=188,332\right)$, PWS only $(\mathrm{n}=40,109)$, and PSW and DM $(n=13,025)$. Low-decreasing primary care, compared to consistent use, was associated with shorter survival, and it was more prevalent in PWS (73\% schizophrenia-only vs. 54\% schizophrenia and DM vs. 52\% DM-only). Increasing use, associated with improved survival, was least common among PWS (4\% vs. 8\% schizophrenia-DM vs. $7 \%$ DM-only). Weiss, et al. ${ }^{37}$ who are cited above, found no significant differences in appropriateness of care assessed as: use of a hypoglycemic medication for patients with a glycosylated hemoglobin (HbAlc) level greater than seven percent, use of an angiotensin-converting enzyme (ACE) inhibitor or angiotensin receptor blocker (ARB) by all patients, use of an antihypertensive medication among patients with HTN, use of a lipidlowering agent among patients with hyperlipidemia, and use of aspirin by all patients. PWS received an overall profile of pharmacological therapy related to cardiac risk factors that was similar to that for persons with DM without schizophrenia. Persons with hyperlipidemia in the two groups were equally likely to receive some form of lipid lowering therapy, however, PWS were significantly more likely to receive one of the older, non-statin agents $(\mathrm{OR}=1.85, \mathrm{p}<0.05)$. Despite appropriate care, there was a significant difference between the two measures of treatment effectiveness: cholesterol levels below $200 \mathrm{mg} / \mathrm{dL}(\mathrm{OR}=0.61,95 \%$ CI $0.45-0.85)$ and LDL less than $130 \mathrm{mg} / \mathrm{dL}(\mathrm{OR}=0.63,95 \%$ CI $0.42-0.93)$ were less prevalent in PWS. Nasrallah, et al.$^{79}$ found that, in PWS recruited for the Clinical Antipsychotic Trials of Intervention Effectiveness (CATIE) study, rates of non-treatment ranged from 30.2 percent for DM, to 62.4 percent for HTN, and 88.0 percent for dyslipidemia. Kreyenbuhl, et al., ${ }^{80}$ in a study of 50 PWS with 
DM compared to persons with DM alone, found less than half of the persons with DM, both with and without schizophrenia, met recommended goals for cholesterol levels or blood pressure control. PWS with DM were less likely to be prescribed cholesterol-lowering statin medications, ACE inhibitors, and ARB agents compared to persons with DM alone.

There are several suggested possible explanations to this service gap, that may be patient (or disease)-related and physician-related. PWS may have difficulties in interpreting and communicating their somatic symptoms, may express inadequate help-seeking behavior and may avoid discussing their medical issues with health care providers. ${ }^{81}$ These stem from schizophrenia symptoms, including cognitive impairment, social isolation and lack of social skills, suspicion or paranoia and negative symptoms (i.e., inactivity, lack of motivation). PWS may perform more poorly when compared to persons without schizophrenia in different intellectual domains (e.g., IQ, attention, memory, language and executive functions). ${ }^{82}$ These deficits may begin years before the psychotic symptoms become evident ${ }^{83,84}$ Some authors claimed that these cognitive deficits constitute the core of schizophrenia. ${ }^{85}$ Cognitive impairment may affect social cognition. ${ }^{86}$

Understanding the differences between general medical versus psychiatric care (fragmentation of health services) and overcoming administrative obstacles may be difficult for PWS. ${ }^{81}$ PWS may have difficulties with understanding medical instructions in emergency room settings. ${ }^{87}$ This may affect adherence with medical care.

When PWS do seek care, some factors may also make it less likely that they receive good medical care. Medical staff may stigmatize PWS (and their relatives) and hold negative attitudes towards them, ${ }^{88,89}$ that may affect decision-making processes. When treating PWS, physical complaints may not be the focus of attention of health providers or may be neglected and misattributed to the psychiatric diagnoses, known as "diagnostic overshadowing". ${ }^{90}$ Physicians may not offer PWS the same treatment plan as they would offer persons without severe mental disorder because of stigma and "therapeutic nihilism", described by PWS and their relatives as abandonment. ${ }^{91,92}$

\section{CONCLUSIONS AND RECOMMENDATIONS}

Our review included a diversity of studies with different methodologies (cohort, case-control, retrospective) conducted in different countries. Although this review is time-limited (between 2006-2012) and included only published papers in English, in general, all of the reviewed studies 
regarding CVD mortality found that PWS have increased risk of CVD mortality. Additionally, most, but not all of the studies found increased rates of CVD behavioral risk factors (i.e., smoking, sedentary life style/less physical activity, increased BMI) in PWS. Although the international community has declared and endorsed its obligation to protect the rights of persons with mental illness and to promote health care and services to these populations, still PWS are exposed to discrimination, to shorter life expectancy and to worse morbidity outcomes. PWS who are service users and their families, clinicians and policy makers all have the responsibility to correct this situation.

In order to do so, and in light of the special needs and considerations regarding PWS, we outline the following general recommendations. Firstly, severe mental illness such as schizophrenia should be addressed as a CVD risk factor, or "risk equivalent" for CVD. ${ }^{91}$ Awareness of this association should be implemented in routine psychiatric and general medicine practice (including internal medicine, family doctors/general practitioners, and cardiology) as well as at national levels for policy makers. Regular screening for cardiovascular risk factors was already recommended by international associations' guidelines. ${ }^{93}$ Primary prevention is an important potential in successful CVD mortality reduction in individuals with severe mental illness, although this may be a challenge for clinicians. ${ }^{94,95}$

Secondly, cardiovascular morbidity and mortality should be referred to as a measurable endpoint for treatment. Medical service deliverers should integrate these data with other "traditional" endpoints regarding the treatment of PWS (i.e., survival time in the community, cumulative time in hospital, medication use). This endpoint should be addressed on the research level as well. ${ }^{93}$ As our search results indicate, many studies are not epidemiological and do not include a comparison group (25 studies without a comparison group versus 37 relevant studies with comparison).

These two points lead to the conclusion that better integration of medical and psychiatric care of PWS is advisable. ${ }^{96}$ Better communication between different physicians (e.g., primary physicians, endocrinologists, and cardiologists) and mental health professionals who treat PWS should be encouraged.$^{94}$ This can be accompanied with technological advances (i.e., unified electronic medical record). Understanding of suggested treatment and adherence to recommendations in PWS may be improved if relatives and friends accompany the patient in medical settings. ${ }^{87}$

These recommendations all align with international declarations and with the basic goal of securing the health and health rights of persons who face severe psychiatric disorders. 
Acronyms List:

$\mathrm{AP}=$ antipsychotic

$\mathrm{BMI}=$ body mass index

$\mathrm{CVD}=$ cardiovascular disorders

$\mathrm{DM}=$ diabetes mellitus

$\mathrm{HR}=$ hazard ratio

$\mathrm{HTN}=$ hypertension

MetS = metabolic syndrome

$\mathrm{MI}=$ myocardial infarction

NHANES $=$ National Health and Nutrition Examination Survey

$\mathrm{OR}=$ odds ratio

PMR $=$ proportional morbidity ratio

PWS $=$ persons with schizophrenia

SES = socio-economic status

SFI = social fragmentation index

$\mathrm{SGA}=$ second generation antipsychotic medication

SMR $=$ standardized mortality ratio

$\mathrm{RR}=$ relative risk

Acknowledgements: The authors wish to thank Prof. Itzhak Levav for helpful remarks, endless patience and valuable comments.

Conflicts of Interest: None declared.

\section{About the Authors:}

Dr. Anat Fleischman, MD, earned her medical degree from Tel-Aviv University and is currently a $\mathrm{PhD}$ candidate at the same university. She is a psychiatrist since 2005 and currently works at the Dual Pathology Department in Yaffo, Israel. Her main research concerns psychotic disorders, addiction and gender medicine, with a special interest in victims of prostitution and human trafficking.

Dr. Ido Lurie, MD, is a psychiatrist since 2005 with an MD from Tel Aviv University. He currently completes his Master in Public Health degree at the same university. He currently works as the deputy manager of the Outpatient Clinic Ambulatory Service in Abarbanel Mental Health Center in Bat-Yam, Israel. Dr. Lurie volunteers as the medical director of the Open Clinic for Work Migrants \& Asylum Seekers/ Physicians for Human Rights - Israel Association. His main research concerns are mental health and illness, immigration, human rights, stigma and socio-economic inequality.

Dr. Lurie was awarded best poster presentation on his study "Psychosocial Rehabilitation and Time-to-Rehospitalization in Schizophrenia" (Israeli Psychiatric Association, 2012) and an award for outstanding residency achievements (Israeli Psychiatric Association, 2009). 


\section{REFERENCES}

1. United Nations General Assembly. Universal Declaration of Human Rights. 217 A (III). UN General Assemby; 10 December 1948. Available from URL: http://www.unhcr.org/refworld/docid/3ae6b3712c.html (accessed 9 December 2012).

2. United Nations Office of the High Commission for Human Rights. Principles for the protection of persons with mental illness and the improvement of mental health care. Resolution 46/119. UN General Assemby; 17 December 1991. Available from URL: http://www.equalrightstrust.org/view-subdocument/ index.htm?id=465 (accessed 8 July 2013).

3. Brown S. Excess mortality of schizophrenia. A meta-analysis. Br J Psychiatry. 1997;171:502-8.

4. Saha S, Chant D, McGrath J. A systematic review of mortality in schizophrenia: is the differential mortality gap worsening over time? Arch Gen Psychiatry. 2007;64:1123-31.

5. Hennekens CH, Hennekens AR, Hollar D, Casey DE. Schizophrenia and increased risks of cardiovascular disease. Am Heart J. 2005;150:1115-21.

6. Roger VL, Go AS, Lloyd-Jones DM, Benjamin EJ, Berry JD, et al. Heart disease and stroke statistics--2012 update: a report from the American Heart Association. Circulation. 2012; 125:e2-220.

7. Evans A, Tolonen H, Hense HW, Ferrario M, Sans S, Kuulasmaa K; WHO MONICA Project. Trends in coronary risk factors in the WHO MONICA project. Int J Epidemiol. 2001;30:S35-40.

8. Yusuf S, Hawken S, Ounpuu S, Dans T, Avezum A, et al. Effect of potentially modifiable risk factors associated with myocardial infarction in 52 countries (the INTERHEART study): case-control study. Lancet. 2004;364:937-52.

9. Greenland P, Knoll MD, Stamler J, Neaton JD, Dyer AR, et al. Major risk factors as antecedents of fatal and nonfatal coronary heart disease events. JAMA. 2003;290:891-7.

10. Khot UN, Khot MB, Bajzer CT, Sapp SK, Ohman EM, et al. Prevalence of conventional risk factors in patients with coronary heart disease. JAMA. 2003;290:898-904.

11. World Health Organization. Global health risks: mortality and burden of disease attributable to selected major risks. WHO: 2009. Available from URL: www. who.int/healthinfo/global_burden_disease/GlobalHealthRisks_report_full. pdf (accessed 8 July 2013).

12. Wu SI, Chen SC, Juang JJ, Fang CK, Liu SI, et al. Diagnostic procedures, revascularization, and inpatient mortality after acute myocardial infarction in patients with schizophrenia and bipolar disorder. Psychosom Med. 2013;75: 52-9.

13. Ratliff JC, Palmese LB, Reutenauer EL, Srihari VH, Tek C. Obese schizophrenia spectrum patients have significantly higher 10-year general cardiovascular risk and vascular ages than obese individuals without severe mental illness. Psychosomatics. 2013;54:67-73. 
14. Morden NE, Lai Z, Goodrich DE, MacKenzie T, McCarthy JF, et al. Eight-year trends of cardiometabolic morbidity and mortality in patients with schizophrenia. Gen Hosp Psychiatry. 2012;34:368-79.

15. Lahti M, Tiihonen J, Wildgust H, Beary M, Hodgson R, et al. Cardiovascular morbidity, mortality and pharmacotherapy in patients with schizophrenia. Psychol Med. 2012;12:1-11.

16. Laursen TM, Nordentoft M. Heart disease treatment and mortality in schizophrenia and bipolar disorder - changes in the Danish population between 1994 and 2006. J Psychiatr Res. 2011;45:29-35.

17. Kelly DL, McMahon RP, Liu F, Love RC, Wehring HJ, et al. Cardiovascular disease mortality in patients with chronic schizophrenia treated with clozapine: a retrospective cohort study. J Clin Psychiatry. 2010;71:304-11.

18. Brown S, Kim M, Mitchell C, Inskip H. Twenty-five year mortality of a community cohort with schizophrenia. Br J Psychiatry. 2010;196:116-21.

19. Kilbourne AM, Morden NE, Austin K, Ilgen M, McCarthy JF, et al. Excess heart-disease-related mortality in a national study of patients with mental disorders: identifying modifiable risk factors. Gen Hosp Psychiatry. 2009;31: 555-63.

20. Tokuda Y, Obara H, Nakazato N, Stein GH. Acute care hospital mortality of schizophrenic patients. J Hosp Med. 2008;3:110-6.

21. Fors BM, Isacson D, Bingefors K, Widerlov B. Mortality among persons with schizophrenia in Sweden: an epidemiological study. Nord J Psychiatry. 2007; 61:252-9.

22. Laursen TM, Munk-Olsen T, Nordentoft M, Mortensen PB. Increased mortality among patients admitted with major psychiatric disorders: a register-based study comparing mortality in unipolar depressive disorder, bipolar affective disorder, schizoaffective disorder, and schizophrenia. J Clin Psychiatry. 2007;68:899-907.

23. Vancampfort D, Probst M, Scheewe T, De Herdt A, Sweers K, et al. Relationships between physical fitness, physical activity, smoking and metabolic and mental health parameters in people with schizophrenia. Psychiatry Res. 2013;207:25-32.

24. Lee J, Nurjono M, Wong A, Salim A. Prevalence of metabolic syndrome among patients with schizophrenia in singapore. Ann Acad Med Singapore. 2012;41: 457-62.

25. Kodesh A, Goldshtein I, Gelkopf M, Goren I, Chodick G, Shalev V. Epidemiology and comorbidity of severe mental illnesses in the community: findings from a computerized mental health registry in a large Israeli health organization. Soc Psychiatry Psychiatr Epidemiol. 2012;47:1775-82.

26. Schoepf D, Potluri R, Uppal H, Natalwala A, Narendran P, Heun R. Type-2 diabetes mellitus in schizophrenia: increased prevalence and major risk factor of excess mortality in a naturalistic 7-year follow-up. Eur Psychiatry. 2012; 27:33-42. 
27. Jin H, Folsom D, Sasaki A, Mudaliar S, Henry R, et al. Increased Framingham 10 -year risk of coronary heart disease in middle-aged and older patients with psychotic symptoms. Schizophr Res. 2011;125:295-9.

28. Yazici MK, Anil Yagcioglu AE, Ertugrul A, Eni N, Karahan S, et al. The prevalence and clinical correlates of metabolic syndrome in patients with schizophrenia: findings from a cohort in Turkey. Eur Arch Psychiatry Clin Neurosci. 2011;261:69-78.

29. Chwastiak LA, Rosenheck RA, Kazis LE. Association of psychiatric illness and obesity, physical inactivity, and smoking among a national sample of veterans. Psychosomatics. 2011;52:230-6.

30. McClave AK, McKnight-Eily LR, Davis SP, Dube SR. Smoking characteristics of adults with selected lifetime mental illnesses: results from the 2007 National Health Interview Survey. Am J Public Health. 2010;100:2464-72.

31. Vinogradova Y, Coupland C, Hippisley-Cox J, Whyte S, Penny C. Effects of severe mental illness on survival of people with diabetes. Br J Psychiatry. 2010;197:272-7.

32. Ferreira L, Belo A, Abreu-Lima C. A case-control study of cardiovascular risk factors and cardiovascular risk among patients with schizophrenia in a country in the low cardiovascular risk region of Europe. Rev Port Cardiol. 2010;29:1481-93.

33. Saarni SE, Saarni SI, Fogelholm M, Heliovaara M, Perala J, et al. Body composition in psychotic disorders: a general population survey. Psychol Med. 2009;39:801-10.

34. Callaghan RC, Boire MD, Lazo RG, McKenzie K, Cohn T. Schizophrenia and the incidence of cardiovascular morbidity: a population-based longitudinal study in Ontario, Canada. Schizophr Res. 2009;115:325-32.

35. Weber NS, Cowan DN, Millikan AM, Niebuhr DW. Psychiatric and general medical conditions comorbid with schizophrenia in the National Hospital Discharge Survey. Psychiatr Serv. 2009;60:1059-67.

36. Birkenaes AB, Opjordsmoen S, Brunborg C, Engh JA, Jonsdottir H, et al. The level of cardiovascular risk factors in bipolar disorder equals that of schizophrenia: a comparative study. J Clin Psychiatry. 2007;68:917-23.

37. Weiss AP, Henderson DC, Weilburg JB, Goff DC, Meigs JB, et al. Treatment of cardiac risk factors among patients with schizophrenia and diabetes. Psychiatr Serv. 2006;57:1145-52.

38. Martin Otano L, Barbadillo Izquierdo L, Galdeano Mondragon A, Alonso Pinedo M, Querejeta Ayerdi I. After six months of anti-psychotic treatment: is the improvement in mental health at the expense of physical health? Rev Psiquiatr Salud Ment. 2013;6:26-32. [In Spanish]

39. Strom BL, Eng SM, Faich G, Reynolds RF, D’Agostino RB, et al. Comparative mortality associated with ziprasidone and olanzapine in real-world use among 18,154 patients with schizophrenia: The Ziprasidone Observational Study of Cardiac Outcomes (ZODIAC). Am J Psychiatry. 2011;168:193-201. 
40. Truyers C, Buntinx F, De Lepeleire J, De Hert M, Van Winkel R, et al. Incident somatic comorbidity after psychosis: results from a retrospective cohort study based on Flemish general practice data. BMC Fam Pract. 2011;12:132.

41. Woo YS, Kim W, Chae JH, Yoon BH, Bahk WM. Blood pressure changes during clozapine or olanzapine treatment in Korean schizophrenic patients. World J Biol Psychiatry. 2009;10:420-5.

42. Jerrell JM, McIntyre RS, Tripathi A. Incidence and costs of cardiometabolic conditions in patients with schizophrenia treated with antipsychotic medications. Clin Schizophr Relat Psychoses. 2010;4:161-8.

43. Tiihonen J, Lonnqvist J, Wahlbeck K, Klaukka T, Niskanen L, et al. 11-year follow-up of mortality in patients with schizophrenia: a population-based cohort study (FIN11 study). Lancet. 2009;374:620-7.

44. Newcomer JW, Campos JA, Marcus RN, Breder C, Berman RM, et al. A multicenter, randomized, double-blind study of the effects of aripiprazole in overweight subjects with schizophrenia or schizoaffective disorder switched from olanzapine. J Clin Psychiatry. 2008;69:1046-56.

45. Tirupati S, Chua LE. Obesity and metabolic syndrome in a psychiatric rehabilitation service. Aust N Z J Psychiatry. 2007;41:606-10.

46. Hagg S, Lindblom Y, Mjorndal T, Adolfsson R. High prevalence of the metabolic syndrome among a Swedish cohort of patients with schizophrenia. Int Clin Psychopharmacol. 2006;21:93-8.

47. Joukamaa M, Heliovaara M, Knekt P, Aromaa A, Raitasalo R, Lehtinen V. Schizophrenia, neuroleptic medication and mortality. Br J Psychiatry. 2006; 188:122-7.

48. Lamberti JS, Olson D, Crilly JF, Olivares T, Williams GC, et al. Prevalence of the metabolic syndrome among patients receiving clozapine. Am J Psychiatry. 2006;163:1273-6.

49. Dohrenwend BP, Levav I, Shrout PE, Schwartz S, Naveh G, et al. Socioeconomic status and psychiatric disorders: the causation-selection issue. Science. 1992; 255:946-52.

50. Werner S, Malaspina D, Rabinowitz J. Socioeconomic status at birth is associated with risk of schizophrenia: population-based multilevel study. Schizophr Bull. 2007;33:1373-8.

51. Os JV, Driessen G, Gunther N, Delespaul P. Neighbourhood variation in incidence of schizophrenia. Br J Psychiatry. 2000;176:243-8.

52. Kohn R, Dohrenwend BP, Mirotznik J. Epidemiological findings on selected psychiatric disorders in the general population. In: Dohrenwend BP, (editor). Adversity, Stress and Psychopathology. New York: Oxford University Press; 1998. p.235-84.

53. Boydell J, Os J, McKenzie K, Murray RM. The association of inequality with the incidence of schizophrenia. Soc Psychiat Epidemiol. 2004;39:597-9.

54. Clark AM, DesMeules M, Luo W, Duncan AS, Wielgosz A. Socioeconomic status and cardiovascular disease: risks and implications for care. Nat Rev Cardiology. 2009;6:712-22. 
55. Kaplan GA, Keil JE. Socioeconomic factors and cardiovascular disease: a review of the literature. Circulation. 1993;88:1973-98.

56. Avendano M, Kunst AE, Huisman M, Lenthe FV, Bopp M, et al. Socioeconomic status and ischaemic heart disease mortality in 10 western European populations during the 1990s. Heart. 2006;92:461-7.

57. Gerber Y, Benyamini Y, Goldbourt U, Drory Y. Neighborhood socioeconomic context and long-term survival after myocardial infarction. Circulation. 2010; 121:375-83.

58. Robbins JM, Vaccarino V, Zhang H, Kasl SV. Socioeconomic status and type 2 diabetes in African American and non-Hispanic white women and men: evidence from the Third National Health and Nutrition Examination Survey. Am J Public Health. 2001;91:76-83.

59. Jotkowitz AB, Rabinowitz G, Segal AR, Weitzman R, Epstein L, Porath A. Do patients with diabetes and low socioeconomic status receive less care and have worse outcomes? A national study. Am J Med. 2006;119:665-9.

60. Rabi D, Edwards A, Southern D, Svenson L, Sargious P, et al. Association of socio-economic status with diabetes prevalence and utilization of diabetes care services. BMC Health Serv Res. 2006;6:124.

61. Lee TC, Glynn RJ, Peña JM, Paynter NP, Conen D, et al. Socioeconomic status and incident type 2 diabetes mellitus: data from the Women's Health Study. PLoS One. 2011;6:e27670.

62. Brummett BH, Babyak MA, Siegler IC, Shanahan M, Harris KM, et al. Systolic blood pressure, socioeconomic status, and biobehavioral risk factors in a nationally representative US young adult sample. Hypertension. 2011;58:161-6.

63. Colhoun HM, Hemingway H, Poulter NR. Socio-economic status and blood pressure: an overview analysis. J Hum Hypertens. 1998;12:91-110.

64. Qi V, Phillips S, Hopman W. Determinants of a healthy lifestyle and use of preventive screening in Canada. BMC Public Health. 2006;6:275.

65. Wang Y, Beydoun MA. The obesity epidemic in the United States--gender, age, socioeconomic, racial/ethnic, and geographic characteristics: a systematic review and meta-regression analysis. Epidemiol Rev. 2007;29:6-28.

66. Najman JM, Toloo G, Siskind V. Socioeconomic disadvantage and changes in health risk behaviours in Australia: 1989-90 to 2001. Bull World Health Organ. 2006;84:976-84.

67. Castelli WP. Epidemiology of coronary heart disease: the Framingham study. Am J Med. 1984;76:4-12.

68. Lynch J, Davey Smith G, Harper S, Bainbridge K. Explaining the social gradient in coronary heart disease: comparing relative and absolute risk approaches. J Epidemiol Community Health. 2006;60:436-41.

69. Allardyce J, Gilmour H, Atkinson J, Rapson T, Bishop J, McCreadie RG. Social fragmentation, deprivation and urbanicity: relation to first-admission rates for psychoses. Br J Psychiatry. 2005;187:401-6.

70. Lögdberg B, Nilsson LL, Levander MT, Levander S. Schizophrenia, neighbourhood, and crime. Acta Psychiatr Scand. 2004;110:92-7. 
71. Curtis S, Copeland A, Fagg J, Congdon P, Almog M, Fitzpatrick J. The ecological relationship between deprivation, social isolation and rates of hospital admission for acute psychiatric care: a comparison of London and New York City. Health Place. 2006;12:19-37.

72. Stjärne MK, Ponce de Leon A, Hallqvist J. Contextual effects of social fragmentation and material deprivation on risk of myocardial infarctionresults from the Stockholm Heart Epidemiology Program (SHEEP). Int J Epidemiol. 2004;33:732-41.

73. Oud M, Meyboom-de Jong B. Somatic diseases in patients with schizophrenia in general practice: their prevalence and health care. BMC Fam Pract. 2009; 10:32.

74. Mitchell AJ, Malone D, Doebbeling CC. Quality of medical care for people with and without comorbid mental illness and substance misuse: systematic review of comparative studies. Br J Psychiatry. 2009;194:491-9.

75. Kilbourne AM, McCarthy JF, Post EP, Welsh D, Pincus HA, et al. Access to and satisfaction with care comparing patients with and without serious mental illness. Int J Psychiatry Med. 2006;36:383-99.

76. Mitchell AJ, Lawrence D. Revascularisation and mortality rates following acute coronary syndromes in people with severe mental illness: comparative metaanalysis. Br J Psychiatry. 2011;198:434-41.

77. Roberts L, Roalfe A, Wilson S, Lester H. Physical health care of patients with schizophrenia in primary care: a comparative study. Fam Pract. 2007;24:3440.

78. Copeland LA, Zeber JE, Wang CP, Parchman ML, Lawrence VA, et al. Patterns of primary care and mortality among patients with schizophrenia or diabetes: a cluster analysis approach to the retrospective study of healthcare utilization. BMC Health Serv Res. 2009;9:127.

79. Nasrallah HA, Meyer JM, Goff DC, McEvoy JP, Davis SM, et al. Low rates of treatment for hypertension, dyslipidemia and diabetes in schizophrenia: data from the CATIE schizophrenia trial sample at baseline. Schizophr Res. 2006; $86: 15-22$.

80. Kreyenbuhl J, Dickerson FB, Medoff DR, Brown CH, Goldberg RW, et al. Extent and management of cardiovascular risk factors in patients with type 2 diabetes and serious mental illness. J Nerv Ment Dis. 2006;194:404-10.

81. Goldman LS. Medical illness in patients with schizophrenia. J Clin Psychiatry. 1999;60 Suppl 21:10-5.

82. Fioravanti M, Carlone O, Vitale B, Cinti M, Clare L. A meta-analysis of cognitive deficits in adults with a diagnosis of schizophrenia. Neuropsychol Rev. 2005;15:73-95.

83. Reichenberg A, Weiser M, Rapp MA, Rabinowiz J, Caspi A, et al. Elaboration on premorbid intellectual performance in schizophrenia: premorbid intellectual decline and risk for schizophrenia. Arch Gen Psychiatry. 2005;62: 1297-304. 
84. Woodberry KA, Giuliano AJ, Seidman LJ. Premorbid IQ in schizophrenia: a meta-analytic review. Am J Psychiatry. 2008;165:579-87.

85. Elvevåg B, Goldberg TE. Cognitive impairment in schizophrenia is the core of the disorder. Crit Rev Neurobiol. 2000;14:1-21.

86. Savla GN, Vella L, Armstrong CC, Penn DL, Twamley EW. Deficits in domains of social cognition in schizophrenia: a meta-analysis of the empirical evidence. Schizophr Bull. 2012 Sep 4; epub ahead of print.

87. Nitzan U, Hirsch E, Walter G, Lurie I, Aviram S, Bloch Y. Comprehension and companionship in the emergency department as predictors of treatment adherence. Australas Psychiatry. 2012;20:112-6.

88. Arvaniti A, Samakouri M, Kalamara E, Bochtsou V, Bikos C, Livaditis M. Health service staff's attitudes towards patients with mental illness. Soc Psychiat Epidemiol. 2009;44:658-65.

89. Thornicroft G, Rose D, Kassam A. Discrimination in health care against people with mental illness. Int Rev Psychiatry. 2007;19:113-22.

90. Jones S, Howard L, Thornicroft G. 'Diagnostic overshadowing': worse physical health care for people with mental illness. Acta Psychiatr Scand. 2008;118: 169-71.

91. Morden NE, Mistler LA, Weeks WB, Bartels SJ. Health care for patients with serious mental illness: family medicine's role. J Am Board Fam Med. 2009; 22:187-95.

92. González-Torres M, Oraa R, Arístegui M, Fernández-Rivas A, Guimon J. Stigma and discrimination towards people with schizophrenia and their family members. Soc Psychiat Epidemiol. 2007;42:14-23.

93. De Hert M, Dekker JM, Wood D, Kahl KG, Holt RI, Moller HJ. Cardiovascular disease and diabetes in people with severe mental illness position statement from the European Psychiatric Association (EPA), supported by the European Association for the Study of Diabetes (EASD) and the European Society of Cardiology (ESC). Eur Psychiatry. 2009;24:412-24.

94. Newcomer JW, Hennekens CH. Severe mental illness and risk of cardiovascular disease. JAMA. 2007;298:1794-6.

95. Davidson M. Risk of cardiovascular disease and sudden death in schizophrenia. J Clin Psychiatry. 2002;63 Suppl 9:5-11.

96. Fleischhacker WW, Cetkovich-Bakmas M, De Hert M, Hennekens CH, Lambert $\mathrm{M}$, et al. Comorbid somatic illnesses in patients with severe mental disorders: clinical, policy, and research challenges. J Clin Psychiatry. 2008;69:514-9. 